\title{
Infografía audiovisual: de la imagen al espacio
}

\author{
Rafael RÀFOLS CABRISSES \\ Universidad Ramon Llull / Universidad Autónoma de Barcelona \\ rafelrc@blanquerna.url.edu
}

Recibido: $21 / 02 / 2011$

Aceptado: 19/07/2011

\section{Resumen}

El desarrollo de la tecnología digital aplicada a la creación y manipulación de la imagen ha alcanzado un nivel que no se corresponde con su uso en la construcción de las noticias en el medio audiovisual. Diferentes circunstancias pueden explicar esta situación y de entre ellas destacaría la consideración de la infografia como un medio solo para crear imágenes cuando, desde mi punto de vista, debería entenderse sobretodo como un medio para la construcción de espacios.

Palabras clave: Diseño digital, infografia, diseño e información, espacio audiovisual.

\section{Audio-visual infography: from image to space}

\begin{abstract}
The development of digital technology in the creation and manipulation of image has achieved such a level that doesn't correspond to its current use in the construction of audio-visual news. A variety of circumstances can explain this situation and, among them, I would like to emphasize the fact that infography is only considerate as a mean to create images, when, under my point of view, it should be understood, above all, as a mean to construct spaces.
\end{abstract}

Keywords: animation graphics, infography, information design, audio-visual space.

\section{Referencia normalizada}

RÀFOLS CABRISSES Rafael (2011): "Infografía audiovisual: de la imagen al espacio". Estudios sobre el mensaje periodístico. Vol. 17, núm. 2, págs.: 569-579. Madrid, Servicio de Publicaciones de la Universidad Complutense.

Sumario: 1. Introducción. 2. Objetivos y metodología. 3. Análisis de la situación. 3.1. Convergencia. televisión y Internet. 3.2. Digitalización de las redacciones. 3.3. Fascinación tecnológica. 4. De la imagen al espacio. 5. Conclusiones. 6. Referencias bibliográficas.

\section{Introducción}

En nuestra sociedad la imagen está adquiriendo un mayor importancia en la comunicación de la mano de las nuevas tecnologías, pero en el terreno de la información audiovisual parece que hay un desequilibrio entre las posibilidades que ha alcanzado dicha tecnología y su uso en la mejora de la comunicación. En la era del Informacionalismo (CASTELLS, 2006) el desarrollo de la tecnología informática en el tratamiento, la manipulación y la creación de imágenes ha llegado a unos niveles que representan un instrumento potencial de pleno derecho para ser considerado en la elaboración de la información diaria audiovisual.

El concepto más preciso para definir esta capacidad tecnológica y sus posibilidades de trasmitir información es el de infografía, que ha tenido su desarrollo teórico a partir de su uso en los medios de la prensa escrita y más recientemente en el de Inter- 
net $^{1}$. En el ámbito de la información audiovisual ${ }^{2}$ el tema presenta características diferenciadas cuya comprensión debemos hacerla situándonos plenamente en el terreno del audiovisual. Es en este espacio que nos proponemos desarrollarlo, explorando sus posibilidades comunicativas.

Aquí vamos a referirnos específicamente a la infografía en los informativos audiovisuales diarios (dejando de lado otros terrenos de la información audiovisual como el reportaje, el documental, etc.) y dentro de este ámbito (conocido por diversidad de nombres como telediarios, telenoticias, etc.) nos referimos específicamente a la construcción de la noticia misma y no de otras intervenciones de imagen gráfica que suelen tener lugar en estos mismos programas ${ }^{3}$.

\section{Objetivos y metodología}

En la era de los cambios tecnológicos la imagen en la construcción de las noticias continua siendo la imagen capturada con una cámara de vídeo mientras otras formas de construcción de la imagen que proporcionan las nuevas tecnologías, continúan mayoritariamente a un lado, lo que pone de manifiesto un desfase entre las posibilidades y su uso en la comunicación.

Nos proponemos analizar el estado de la cuestión haciendo un repaso a la literatura teórica, necesariamente de los últimos años, que trata específicamente sobre el tema de la infografia audiovisual y también de aquella que trata el tema en el marco general del periodismo audiovisual.

A ello se le sumará una aproximación a la convergencia entre la televisión e Internet, por su especial relevancia respecto de nuestra aproximación, así como a la digitalización de las redacciones y a los cambios tecnológicos que están afectando a la televisión, por su relación con el tema.

${ }^{1}$ Para obtener distintas perspectivas sobre el tema pero especialmente a la definición del concepto, véanse De PABlos, 1998; VALERo, 2001 y 2008 donde se trata específicamente el tema

${ }^{2}$ Apréciese que cuando hablamos de Internet nos situamos en el ámbito de la infografía estática o a lo sumo con algunos movimientos asociados a la imagen, ya que es en este sentido como ha sido básicamente encuadrado hasta la fecha. Sin embargo, a lo largo de este trabajo haremos planteamientos en los que situemos Internet plenamente en el contexto audiovisual. Sobre infografía audiovisual véanse VALERO, 2004 y 2009; RÀFOLS, 2005; RÀFOLS y PeRALTA, 2007. Si bien en estos artículos se habla específicamente sobre el tema desde diferentes perspectivas, a los largo del artículo aparecerán diversas citas de libros y artículos donde hay referencias al tema en el marco del periodismo audiovisual.

${ }^{3}$ Los elementos gráficos en los informativos audiovisuales no han hecho más que ir aumentando y haciéndose más complejos a medida que la tecnología audiovisual avanzaba. Así, y sin ánimo de ser exhaustivos, nos encontramos con la cabecera del programa; diverso tipo de ráfagas que se utilizan a modo de puntuación para separar noticias o grupos de noticias; imágenes que pueden aparecer mientras el presentador introduce la noticia haciendo referencia a la misma; los mapas meteorológicos, etc. En muchos aspectos podemos decir que su presencia está directamente proporcionada con las pretensiones del programa. 
Este análisis de la situación nos ha de servir para situarnos donde estamos antes de plantearnos la hipótesis de si puede mejorarse la capacidad comunicativa del actual enfoque de la infografía en los informativos audiovisuales diarios para reorientar su utilización. Para ello vamos a aportar que hay posibilidades de utilizar estas tecnologías desde otro ángulo que ponga de manifiesto nuevos planteamientos en la utilización del espacio audiovisual.

\section{Análisis de la situación}

La aproximación al tema de la infografía por parte de académicos y periodistas es muy amplia y va desde los que ni lo mencionan hasta los que les ven grandes posibilidades. En medio hay todo un abanico de diferentes posiciones sobre el tema. Podría decirse que existe un consenso generalizado sobre su uso y aceptación como herramienta periodística, aunque no sin algún recelo, en los informativos audiovisuales. Hay ya estudios específicos que demuestran su capacidad de aumentar la atención y la capacidad de recordar las noticias por parte de los telespectadores (Fox et al., 2004; SHOVMAN, 2009). Un aspecto bastante determinante en su consideración es cuando el autor plantea la necesidad de que la producción infográfica esté situada en la misma redacción. En los niveles que aquí queremos aproximarnos a la cuestión seria imposible de otra manera.

La infografia en la prensa ha tenido una evolución mucho más importante puesto que al parecer la necesidad que ha tenido la prensa de potenciar la comunicación visual ha empujado su desarrollo, por detrás de la fotografía, por supuesto. En cambio, en el medio audiovisual, al que le es innato el uso de la imagen, el proceso de evolución parece mucho más lento, al mismo tiempo que la mayoría de los autores se la plantean más como una opción que como una necesidad, al considerar la preeminencia de la imagen capturada con cámara de video, cosa que aquí no cuestionamos, y el uso de la infografía como recurso cuando no se dispone de ellas ${ }^{4}$. Si bien este es un planteamiento de la infografía propio del audiovisual y que ha funcionado a lo largo de los últimos veinte años, parece que va llegando el momento de ir enfocando el tema desde nuevas perspectivas.

Un ejemplo de este desfase es que sigue instalado en muchas redacciones el concepto de posproducción para referirse a la infografía, aunque consideramos que el problema no es el nombre en sí ya que forma parte del argot profesional. El término se acuñó en la era analógica antes de que se divulgara la palabra infografia y respondía a la idea de que la producción es la grabación con la cámara de video mientras la producción utilizando software entraba en el ámbito de la posproducción, manteniendo el concepto de secuencia temporal. En la era digital, cuando estamos en disposición de construir imágenes complejas uniendo imágenes de diferentes orígenes, pero todas ellas digitales, la palabra posproducción queda completamente desfasada.

${ }^{4} \mathrm{Si}$ se cumpliera el principio de que cuando no se cuente con imágenes lo suficientemente informativas para visualizar lo que dice la voz en off, estas se crearan digitalmente podríamos darnos por satisfechos, pero la realidad diaria de los informativos nos demuestra que estamos aún lejos de ello. 
No es que el medio audiovisual haya despreciado la infografia como podemos ver por ejemplo en los programas electorales, donde a menudo se hacen grandes despliegues tecnológicos que incluyen un profundo uso de ella. Estos programas no dejan de ser en directo, eso sí, con tiempo de antelación para su preparación ${ }^{5}$.

Estamos también delante de un problema de competencias profesionales puesto que estamos hablando de construir la información colectivamente, pero los periodistas no consideran a los infografos sus pares, cuando no les ven directamente con recelo, como para traspasarles la responsabilidad de elaborar noticias. Como apunta VALERO (2001: 98-100) habrá que ir pensando en esta formación por parte de los infografistas.

Una de las dificultades en su uso es que una mayor complejidad de imagen implica protocolos de trabajo más sofisticados en los mismos tiempos de ejecución (RÀFoLs, 2005: 793), de toda manera la tecnología todavía puede darnos algún empujón en esta dirección. También hay que tener en cuenta que el uso de imagen gráfica puede condicionar, especialmente cuanto más compleja es, la construcción del discurso verbal, ya que necesita unos tiempos de evolución, de permanencia en pantalla y de dar paso a los siguientes elementos que deben completar el conjunto. Una información compleja debe ir construyéndose a medida que la voz en off avanza y debe construirse de principio a final para que el espectador comprenda visualmente también aquello que se le está explicando (RÀFols y PerAlta, 2007: 297). La estructura audiovisual debe articularse de manera que discurso verbal y visual sincronicen el mayor tiempo posible (véase RoDRíGUEZ, 1998).

Independientemente de la valoración de estas imágenes por parte de académicos y periodistas la realidad diaria nos demuestra que su uso es más bien escaso. La necesidad que manifiesten los periodistas de contar con ellas es y será determinante, pero parece que existen otros factores importantes que condicionan su uso.

\subsection{Convergencia televisión y Internet}

De lo que estamos hablando aquí es de transmitir la información en tiempo real, no del medio por el que se haga. Obviamente nos estamos refiriendo a los informativos de televisión por su importancia, ya que no solo tienen grandes audiencias sino que además son la columna vertebral de las cadenas (GuTIÉRREZ et al., 2010: 141). Así nos lo explica Gabriel PéREZ:

"Las noticias son uno de los contenidos más demandados por los telespectadores, lo que asegura el futuro de los telediarios bajo cualquier formato; otra cuestión es como deban estructurarse para su consumo. Por el momento, el telediario, como fórmula estándar para comunicar noticias, tiene excelente salud en la televisión digital, al mismo tiempo que coexiste con otras fórmulas que, cada vez más, gozan de aceptación popular" (PÉREZ, 2010: 39).

${ }^{5}$ La preproducción lo que hace en estos casos es crear unas plantillas que prevean la casuística que se pueda producir y que para el programa en directo se asocian a las bases de datos que se generan tras los cierres de los colegios electorales. Estos datos proporcionaran las formas definitivas dentro de los márgenes previstos. Cada vez más en estos casos se recurre a la imagen sintética $3 \mathrm{~d}$ en tiempo real que genera formas volumétricas. 
En Internet va adquiriendo mayor importancia el audiovisual (SALAVERRíA y SANCHO, 2007: 31-32) aunque a menudo se habla de la información en Internet no teniendo en cuenta su carácter de soporte e ignorando el audiovisual cuando se habla de periodismo y, sin embargo, su presencia no para de crecer en la red ${ }^{6}$. El concepto audiovisual está más asociado a la televisión mientras que el de multimedia lo está a Internet, ambos conceptos no son excluyentes y hay quien apunta que las bases comunicativas del multimedia están ya en la televisión (SALAVERRÍA, 2001: 388-389).

Si bien el carácter dinámico y colaborativo de la red (CASTELLS 2006: 70) podría jugarle una mala pasada a la televisión en este sentido, de lo que estamos hablando depende más de apuestas empresariales ${ }^{7}$, ya que si a menudo se habla del carácter activo que el usuario puede desempeñar en la construcción de su propia información, es preciso tener en cuenta que la mayor parte de la información sigue obteniéndose de forma pasiva y por televisión. Si la información ha de acabar transmitiéndose a través de Internet, los espectadores no van a cambiar necesariamente por ello su actitud a la misma velocidad (GALLARDO y JORGE, 2010: 432).

\subsection{Digitalización de las redacciones}

El proceso de digitalización de la información además de incidir en cada uno de los artilugios propios de la profesión, ha culminado con la digitalización de las redacciones, cuyas consecuencias han tenido mucho más impacto que un simple cambio de formatos y las empresas periodísticas están viviendo grandes procesos de transformación. Es lo que SALAVERRÍA y García (2008) llaman un proceso de convergencia multidimensional que afecta a todos los ámbitos: tecnológico, empresarial, profesional y de contenidos. La digitalización ha sido un paso clave para que el lenguaje periodístico audiovisual pueda hacer un salto cualitativo y cuantitativo en la integración con otros tipos de imágenes y sus posibilidades asociadas.

Nos encontramos también en un momento en que las preocupaciones no están en la transmisión de una información de calidad y rigor, sino que más bien parece que estamos sumidos en un proceso de mayor peso de las ideologías en la transmisión de la información (GUTIÉRREZ et al., 2010: 134) por una lado y de espectacularización y mercantilización de la información (ibid.: 141; CEBRIÁN, 2004: 17-21) por el otro, dando así más valor al impacto de las imágenes. Sin duda la enorme proliferación de aparatos para la captación de video ha aumentado las posibilidades de obtención de este tipo de imágenes, sin embargo, el problema para la televisión es que con este material lo tiene mal para competir con Internet.

\footnotetext{
${ }^{6}$ Véase http://www.abc.com.py/nota/el-futuro-de-internet-esta-en-el-video/

${ }^{7}$ La edición digital del rotativo Apple Daily http://hk.nextmedia.com/ que se edita en Hong Kong incluye videos con recreaciones de imagen sintética en $3 \mathrm{~d}$ cuando no tienen imágenes gravadas en video. Aunque lo que se hace es un uso espectáculo de la tecnología $3 \mathrm{~d}$ al asociarla a las noticias de mayor impacto social, hecho que ha sido cuestionado desde la profesión periodística. Si bien está lejos de las ideas que aquí queremos proponer, sin embargo, pone de relieve que tecnológicamente es posible.
} 
No pretendamos que los periodistas solucionen los problemas de comunicación de la imagen en movimiento que la teoría no ha hecho y démosles nuevos planteamientos des de donde pueda dar nuevos enfoques a su trabajo. Como dice SALAVERRía (2001: 394): "La nueva frontera digital para el periodismo ya no es tecnológica, sino lingüística, comunicativa.". Un periodista al que cada vez se le pide más ductilidad profesional no le vamos a pedir que además investigue las posibilidades comunicativas de las imágenes gráficas y, no nos engañemos, el periodista está más familiarizado con el lenguaje verbal que con el audiovisual (SAlaVERRía y SANCHO, 2007: 32; SAlAVERRía y GARCÍA, 2008: 13), por otro lado tecnológicamente mucho más manejable.

\subsection{Fascinación tecnológica}

El proceso de innovación de la imagen digital es tan apabullante que estamos extasiados por ella ${ }^{8}$ y nos hemos instalado en la concepción de la tecnología como espectáculo (CEBRiÁn, 2004: 55; RÀFols y Peralta, 2007: 300-301) de manera que lo habitual es hablar de ella por lo incesante de esta innovación. Las mismas cadenas de televisión están más preocupados por la utilización de estas tecnologías para basar sus discursos antes que en la comunicación que transmiten. El mensaje está subyugado a la capacidad de impacto de la imagen, utilizando la fuerza estética innata a las novedades tecnológicas más por su capacidad de atracción que por capacidad de transmitir contenidos. Según Josep M. CATALÀ:

"No estoy hablando del uso partidista de los medios, es decir, de su uso ideológico a cualquier nivel, sino de una cuestión estructural que hace que la tecnología se convierta en discurso antes incluso de que sea empleada de forma discursiva. [...] podemos comprender por qué la sociedad de la comunicación puede llegar a promocionar estructuralmente lo contrario de lo que parecen ser sus intereses fundamentales" (CATALÀ, 2010: 342).

La imagen tecnológicamente compleja no representan ningún tipo de problema para el público, especialmente entre los más jóvenes, sin embargo en el ámbito periodístico aparecen todavía algunos recelos. Si bien son vistas con fascinación, sobretodo por su alto valor tecnológico, su carácter "artístico" o estético les impide estar al mismo nivel que las imágenes obtenidas con una cámara de video ${ }^{9}$. Con suerte aparecen asociadas al concepto de diseño pero como no acaba de entenderse muy bien que significa esto en el terreno audiovisual ${ }^{10}$ tampoco parece una muy buena tarjeta de vi-

\footnotetext{
${ }^{8}$ Acabamos de hacer la transición a la TDT; estamos en la transición del formato 4:3 al 16:9; está surgiendo la tecnología HD; también la tecnología de la visión 3d; la imagen sintética 3d en tiempo real está abriéndose camino; la imagen virtual está introduciéndose en los platós de los programas informativos; la realidad aumentada es otra tecnología que está en aumento, etc.

${ }^{9}$ Existe la idea extendida de identificar el concepto video con la imagen obtenida mediante el uso de una cámara de video, pero hemos de tener presente que el producto que sale de un software de edición o bien de composición (para diferenciar estos conceptos véase Micó, 2006: cap. 2) es también video. Este video puede contener solo imagen obtenida con cámara de video, imagen que ha sido creada con uno o varios software de los que utilizan los infografistas, o bien una mezcla de ambos tipos de imágenes de video. Todo ello es imagen audiovisual digital.

${ }^{10}$ Para una mayor profundización en el tema véase RÀFols y COLOMER, 2003
} 
sita. Son también vistas con recelo por que pueden alterar la realidad, como si hoy no fuera posible alterar la imagen obtenida con cámara de video.

Podemos decir entonces que nos encontramos en la paradoja de estar en el mejor momento des del punto de vista tecnológico y, sin embargo, los proyectos empresariales no parecen capaces de sacarle rentabilidad comunicativa (SALAVERRÍA y GARCÍA, 2008: 2).

\section{De la imagen al espacio}

Ante el momento de impasse en el que al parecer nos encontramos en el uso de la infografía en la difusión de la información audiovisual, quisiera hacer un planteamiento de su uso basado en la idea de utilizar la capacidad de comunicación espacial que es innata a la comunicación gráfica, lo cual se complementa más que compite con el uso de la imagen obtenida con cámara de video. Imagen y espacio son dos conceptos indisociables y aunque la imagen es el aspecto visible de la forma, su percepción lleva implícita la lectura del espacio. No es tanto de esta lectura de lo que queremos hablar aquí sino de su uso en la construcción de la imagen.

La imagen icónica es muy efectiva porqué se lee automáticamente pero tiene limitaciones en lo referente a la comunicación espacial. En cambio la imagen gráfica tiene una relación innata con el espacio y, aunque no sabemos por que mecanismos, sabemos que la suya es una lectura intrínsecamente espacial (TRICKETT y TRAFTON, 2004). Queremos proponer el ver la imagen en términos de espacio, lo que implica una ruptura en su cohesión tal y como la entendemos ahora, lo que nos ofrece la posibilidad de construir imágenes complejas con capacidad de establecer una mayor comunicación con sus destinatarios (CATALÀ, 2010: 253-258).

La tecnología audiovisual digital no es solo una cuestión de herramientas complejas sino que también nos ofrece la posibilidad de percibir nuestro entorno de manera distinta y con ello plantearnos las cosas de manera diferente. Cuando se trata de construir discursos informativos que utilizan la tecnología para interpretar la realidad, como hacen los periodistas, ha de replantearse el papel de la imagen que nos ofrecen dichas herramientas, especialmente cuando como en el audiovisual los discursos verbal y visual interactúan, ya que de su uso eficaz depende la comprensión de estos contenidos. Como nos dice Josep M. CATALÀ:

"Me refiero al antagonismo de los modos visual y verbal de análisis y pensamiento. A medida que las técnicas relacionadas con el ordenador se van imponiendo en todos los campos del saber, se hace cada vez más evidente la importancia del modo visual de comprensión y representación del conocimiento. Podríamos decir que se coloca en primer termino el modo de exposición, como puerta de entrada al significado, puesto que este modo de exposición no es otra cosa que la forma del conocimiento en su sentido más básico" (CATALÀ, 2010: 374).

La magnitud de estos cambios no nos llevan solo a replantearnos la imagen en el conocimiento sino también a un nivel más profundo, ya que como nos dice CATALÀ (2010: 261) estamos percibiendo la realidad a partir de un nuevo modelo mental, que no es fruto de estos cambios tecnológicos sino que los ha propiciado: “...existe una analogía profunda entre nuestra concepción actual del espacio y una determinada tec- 
nología que surge de una forma distinta de pensar la realidad." Si las hemos creado para ello usémoslas, ya que el espectador está preparado para entender el espacio audiovisual de manera compleja. La linealidad del discurso informativo audiovisual necesita elementos de construcción espacial para la asimilación de contenidos, ya que dicha asimilación está ligada a la comprensión del espacio y para hacerlo posible debemos dotar al telespectador del mayor número de medios a nuestro alcance.

En un informativo audiovisual estamos cambiando la ubicación espacial como mínimo en cada noticia, o incluso varias veces dentro de cada una de ellas. La imagen obtenida con cámara de video nos transmite su iconicidad con lo cual obtenemos una decodificación automática pero parcial, ya que solo percibimos el espacio que la contiene. Nos referimos al espacio de su ubicación geográfica, ya que es precisamente la iconicidad de la imagen la que desata los mecanismos mentales de la configuración espacial de dicha imagen y su contextualización, al que esta imagen no puede responder por si sola. Cuando vemos las imágenes icónicas ya damos por supuesto el espacio y ello no es necesariamente así si el receptor no dispone de esquemas mentales donde ubicarlas. Para entender la forma de la imagen necesitamos comprender la estructura a la cual pertenece. En un primer nivel ello se realiza automáticamente con la lectura icónica, pero en un segundo nivel estas estructuras necesitan encontrar encaje en nuestros esquemas mentales (Soengas, 2003: 137; RÀFols y Peralta, 2007: 295) que incluyen la comprehensión espacial.

Dentro del proceso de construcción de la noticia hay que transmitir al espectador la espacialidad contenedora de dichas imágenes para que pueda dotarse de nuevos esquemas mentales, ya que sin ellos la percepción de la imagen, si esta no proviene de un lugar que conozcamos físicamente, tiene un nivel de percepción muy vago, y, por lo tanto, una capacidad de aprehensión insuficiente, especialmente cuando se transmite en tiempo real. Esta desestructuración espacial provoca distanciamiento hacia la información, o lo que es lo mismo: ¿cuanta información retiene el telespectador de toda la multitud de datos que está recibiendo en tiempo real sin posibilidad de pausa?

Para explicar y utilizar el espacio necesitamos construir imágenes complejas en este espacio ambiguo que son las pantallas de ordenador y los monitores de televisión. El suyo es un espacio bidimensional por su realidad física en la que se sitúan las formas, a la vez que también es tridimensional porque en su interior percibimos la profundidad. Bidimensionalidad y tridimensionalidad que además se entrecruzan cuando este espacio se fragmenta. Hay que aprovechar las oportunidades que nos ofrece este espacio ambiguo y complejo que es el audiovisual cuyas posibilidades están abiertas ${ }^{11}$.

Se trata de comunicar con el espacio en una doble dirección: por un lado ser conscientes de la necesidad de explicar los espacios para que el espectador pueda comprender las imágenes en tiempo real, y por otro el uso del espacio audiovisual, es decir, el medio por el que transmitimos la información, de la forma lo más efectiva posible para comunicar no solo espacios geográficos sino conceptos complejos densamente comprimidos en el tiempo. Más que de unir la visión de la imagen y la del espacio se trataría más bien de una concepción visioespacial de la imagen (LOWE y PRAMONO, 2006).

${ }^{11}$ En los terrenos donde más se ha profundizado más en la utilización del espacio audiovisual es en el diseño audiovisual y las graphic movies. 
Estamos planteando un concepto de la infografia más allá de la capacidad que tiene de construir imágenes, cosa que ya ha demostrado. Se ha puesto demasiado énfasis en la infografia como imagen mientras no se la ha aprovechado como configuradora de espacios. Ver y entender el espacio, precisamente para usarlo eficazmente, es una operación más compleja. El espacio no está solo contenido en la imagen sino que es un continente configurador de la imagen. La imagen hay que entenderla en sentido amplio y, sobretodo, no diferenciado de la imagen de video, sino en fusión con ella. Poco sentido tiene, en un planteamiento de estas características, esforzarse en diferenciar donde empieza y donde acaba uno u otro tipo de imagen. El que está menos interesado en esta distinción es el espectador, quien, en cambio, si está interesado en comprender mejor aquello que queremos explicarle.

El uso de la imagen tal y como la proponemos, nos lleva inevitablemente a la profundización en la fragmentación del espacio, que ya tienen plenamente asumido los telespectadores. El problema de la televisión con respecto a Internet está más en superar su concepción básicamente temporal para profundizar en los aspectos espaciales, que sin duda ya están siendo explorados, pero que necesitan nuevos empujes (DíAZ ARIAS, 2009: 70). Quizás en este momento la última frontera que separe televisión y Internet sea la concepción profundamente ligado al tiempo y al espacio que tienen respectivamente, al menos tal y como los conocemos ahora.

\section{Conclusiones}

La conclusión principal es que la infografía audiovisual puede desarrollarse si es concebida desde la perspectiva de su capacidad de configurar espacios para la mejora de la comunicación en los informativos audiovisuales diarios. Persistir en el estado actual de la cuestión es ahondar en el potencial no alcanzado de las nuevas tecnologías y sus posibilidades comunicativas.

Hay que superar el concepto de la infografia limitada a la construcción de imágenes que no se puedan obtener por otros medios y, con una visión amplia de la misma, aprovechar los recursos que nos ofrece en la construcción de la imagen audiovisual compleja. Una vez que las redacciones están digitalizadas la interacción de imágenes de distinta procedencia ya no es un problema, y ello nos permite ahondar en la creación de imágenes donde se fundan lo gráfico y lo icónico, aprovechando las características propias de cada una de ellas, a la vez que se potencian mútuamente al interactuar entre ellas. Dejémonos de extasiarnos con los artificios de la tecnología de la imagen y pongámonos a investigar estas potencialidades que para nada tienen que entrar en conflicto con la ética periodística.

Con la normalización del uso del potencial espacial de la infografía en las redacciones, el espectador tendría más posibilidades de asimilar la gran cantidad de información que se le transmite en tiempo real y, además, una imagen más completa informativamente hablando podría exponer los conceptos espaciales que enmarcan las noticias, sin las cuales es difícil que el espectador cree esquemas mentales o utilice los que posee para la comprensión de la información.

La pantalla audiovisual es un espacio ambiguo y complejo del que puede sacarse provecho una vez que el espectador ya trabaja con nuevos modelos mentales en la 
percepción de la imagen. De ahí se abren líneas de investigación encaminadas a profundizar la relación entre el espacio y la imagen y su relación con la comunicación en la era digital.

\section{Referencias bibliográficas}

CASTELLS, Manuel (2006): "Informacionalismo, redes y sociedad red: una propuesta teórica”, en CASTELLS, Manuel (ed.): La sociedad Red: una visión global. Madrid, Alianza Editorial, pp. 27-75.

CATALÀ, Josep Maria (2008): La forma del real. Introducció als estudis visuals. Barcelona, UOC.

CATALÀ, Josep Maria (2010): La imagen interfaz. Representación audiovisual y conocimiento en la era de la complejidad. Bilbao, Universidad del País Vasco.

CEBRIÁN, Mariano (1983): Fundamentos de la teoría y técnica de la información audiovisual. Madrid, Mezquita.

CEBRIÁN, Mariano (2004): La información en televisión. Obsesión mercantil y política. Barcelona, Gedisa.

DE PABLOS, José Manuel (1998): “Siempre ha habido infografía (3)", en Revista Latina de Comunicación Social: http://cort.as/0YvP. [Consulta: 22 noviembre 2010]

DÍAZ ARIAS, Rafael (2009): "El vídeo en el ciberespacio: usos y lenguaje”, en Comunicar: http://cort.as/0YvM. [Consulta: 14 noviembre 2010]

FOX, Julia et al. (2004): "Picture This: Effects of Graphics on the Processing of Television News", en Journal of Broadcasting \& Electronic Media: http://cort.as/0Yvj. [Consulta: 20 noviembre 2010]

GALLARDO, Jorge y JORGE, Ana (2010): "La baja interacción del espectador de vídeos en Internet: caso Youtube España" [En línea]. Revista Latina de Comunicación Social: http://cort.as/0FHE. [Consulta: 18 noviembre 2010]

GUTIÉRREZ, Begoña et al. (2010): "El tratamiento de las notícias televisivas a debate: de la información a la dramatización", en Revista Latina de Comunicación Social: http://cort.as/0Yvt. [Consulta: 15 noviembre 2010]

LOWE, Richard y PRAMONO, Harto (2006): "Using graphics to support comprehension of dynamic information in texts", en Information Design Journal: http://cort.as/0Yw4. [Consulta: 23 noviembre 2010]

MICÓ, Josep Lluís (2006): Teleperiodisme digital. Barcelona, Trípodos.

PÉREZ, Gabriel (2010): Informar en la e-televisión. Curso básico de periodismo audiovisual. Pamplona, EUNSA

RÀFOLS, Rafael y COLOMER, Antoni (2003): Diseño audiovisual. Barcelona, Gustavo Gili.

RÀFOLS, Rafael (2005): “Grafisme als serveis informatius de TV3”. Trípodos núm. extra, p. 785-794. 
RÀFOLS, Rafael y PERALTA, Miquel (2007): "Noves tecnologies a la televisió: cap una renovació del llenguatge informatiu". Trípodos núm. extra, p. 291-301.

RODRÍGUEZ, Ángel (1998): La dimensión sonora del lenguaje audiovisual. Barcelona, Paidós.

SALAVERRÍA, Ramón (2001): “Aproximación al concepto de multimedia desde los planos comunicativo e instrumental", en Estudios sobre el mensaje periodístico, vol. 7, pp. 383-395. Madrid, Servicio de Publicaciones de la Universidad Complutense de Madrid.

SALAVERRÍA, Ramón y GARCÍA, José Alberto (2008): "La convergencia tecnológica en los medios de comunicación: retos para el periodismo", en Trípodos: http://cort.as/0YwF. [Consulta: 11 noviembre 2010]

SALAVERRÍA, Ramón y SANCHO, Francisco (2007): "Del papel a la Web. Evolución y claves del diseño periodístico en internet", en Diseño periodístico en internet: http://cort.as/0YwJ. [Consulta: 19 noviembre 2010]

SHOVMAN, Mark et al. (2009): "Changing the View: Towards the Theory of Visualisation Comprehension", en Information Visualisation, $200913^{\text {th }}$ International Conference: http://cort.as/0YwM. [Consulta: 23 noviembre 2010]

SOENGAS, Xosé (2003): El tratamiento informativo del lenguaje audiovisual. Madrid, Laberinto.

TRICKETT, Susan Bell y TRAFTON, Gregory (2004): "Spatial Transformations in Graph Comprehension", en Blackwell et.al. (Eds.): Diagram 2004, LNAI 2980: http://cort.as/0YwN. [Consulta: 23 noviembre 2010]

VALERO, José Luís (2001): La Infografia: técnicas, análisis y usos periodísticos. Bellaterra, Universitat Autònoma de Barcelona.

VALERO, José Luís (2004): "El grafismo en la información televisiva”, en Anàlisis: http://cort.as/0YwP. [Consulta: 23 noviembre 2010]

VALERO, José Luís (2008): “Tipología del grafismo informativo", en Estudios sobre el mensaje periodístico, vol.14, pp. 631-648. Madrid, Servicio de Publicaciones de la Universidad Complutense de Madrid.

VALERO, José Luís (2009): "Clasificación del grafismo de contenido en los informativos de televisión", en Trípodos: http://cort.as/0YwT. [Consulta: 12 noviembre 2010] 